\title{
Correction to: Modelling the impact of travel restrictions on COVID-19 cases in Hong Kong in early 2020
}

Wang-Chun Kwok ${ }^{1 \dagger}$, Chun-Ka Wong ${ }^{1 \dagger}$, Ting-Fung Ma², Ka-Wai Ho ${ }^{3}$, Louis Wai-Tong Fan ${ }^{4}$, King-Pui Florence Chan', Samuel Shung-Kay Chan ${ }^{1}$, Terence Chi-Chun Tam ${ }^{1}$ and Pak-Leung Ho ${ }^{5 *}$

\section{Correction to: BMC Public Health (2021) 21:1878.} https://doi.org/10.1186/s12889-021-11889-0

It was highlighted that the in the original article the name of Chun-Ka Wong was incorrectly shown as KaChun Wong. The original article has been updated [1].

\footnotetext{
Author details

'Department of Medicine, Queen Mary Hospital, Hong Kong, SAR, China.

${ }^{2}$ Department of Statistics, University of Wisconsin, Madison, USA.

${ }^{3}$ Department of Astronomy, University of Wisconsin, Madison, USA.

${ }^{4}$ Department of Mathematics, Indiana University, Bloomington, USA.

${ }^{5}$ Department of Microbiology and Carol Yu Centre for Infection, University of

Hong Kong, Hong Kong, SAR, China.
}

Published online: 17 November 2021

\section{Reference}

1. Kwok W-C, et al. Modelling the impact of travel restrictions on COVID-19

cases in Hong Kong in early 2020. BMC Public Health. 2021;21:1878. https:// doi.org/10.1186/s12889-021-11889-0.

\footnotetext{
The original article can be found online at https://doi.org/10.1186/s12889021-11889-0.

* Correspondence: plho@hku.hk

${ }^{+}$Wang-Chun Kwok and Chun-Ka Wong contributed equally to this work.

${ }^{5}$ Department of Microbiology and Carol Yu Centre for Infection, University of Hong Kong, Hong Kong, SAR, China

Full list of author information is available at the end of the article
}

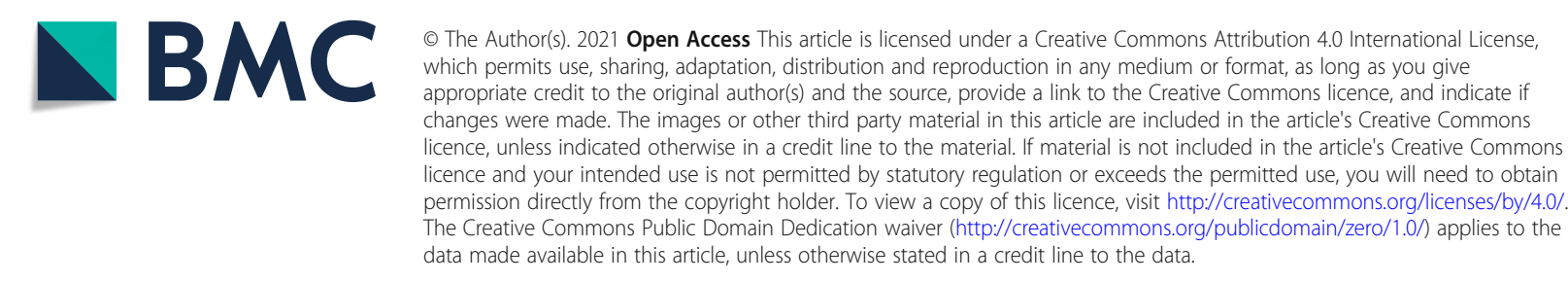

